\title{
PROMOTING INTERAGENCY AND INTERNATIONAL COOPERATION IN COUNTERING HYBRID THREATS
}

\author{
Yantsislav YANAKIEV
}

\begin{abstract}
The editorial article summarises the achievements of the International conference titled "Interagency and International Cooperation in Countering Hybrid Threats." The articles in this volume cover a broad range of issues related to NATO, EU and national experiences in the research and practical activities in countering hybrid warfare.
\end{abstract}

Keywords: Hybrid threats, societal resilience, civil-military interoperability, interagency cooperation.

This volume is the outcome of the International conference titled "Interagency and International Cooperation in Countering Hybrid Threats," co-organised by Defence Advanced Research Institute (DARI) and the Armed Forces Communications and Electronics Association (AFCEA) International, South East European Region, AFCEA Sofia Chapter in Sofia, Bulgaria on 28 - 29 September 2016.

The conference aimed to:

- create a scientific and expert platform for discussion on the diversity of future warfare's aspects and to propose effective ways and means for building integral capabilities to counter hybrid threats

- present an expert assessment on the institutional need of capabilities to countering hybrid threats and possible ways for a cross-agency contribution to their integration

- $\quad$ serve as a driving point of a project for the development a new Vision for the future Bulgarian Armed Forces and Defence in account of the diversified threats.

The main focus of the conference was on how to promote interagency and international cooperation to counter hybrid threats. In this respect, I would like to emphasise on the contribution of vice-admiral Eftimov who presented NATO approach to build 
a potential to counter hybrid threats through cooperation and regional security. In addition, Mr. Deliso discussed risks for the Bulgarian and Macedonian security related to the migrant crisis in 2015 , and stressed the need for improved interagency cooperation to guarantee effective response. Besides, Mr. Nikolic identified some impediments to efficient interagency cooperation at national and international levels in counteracting hybrid threats. Moreover, Mr. Rizov raised the important topic of the benefits and challenges of sharing information about cyber threats, as well as the strengths and weaknesses of different information sharing models. Finally, Dr. Zhekova highlighted the importance of communication between the defence sector and the civil society to build capacity for countering hybrid threats.

The next equally important area of discussions was related to possible approaches to building societal resilience as a means to counter hybrid threats. Prof. Atkinson argues that hybrid warfare has important implications for democratic governance because it is undermined not only by hybrid warfare, but also by actions taken by democratic governments to counter those threats. Prof. Yanakiev, LTC Dimov and Major Bachvarov concluded that the existing stovepipe organization of the security sector institutions is not effective enough to counter hybrid warfare. There is clear need for improved interagency cooperation and coordination, as well as the commitment of the private sector, the civil society, and even each individual citizen.

The next group of articles centres on the conceptual, doctrinal and legal capability developments to counter hybrid threats. Col. Monov and Dr. Karev argue that a new model and methodology for decision-making process to counter hybrid threats is needed at both national and Allied level. In addition, Ms. Mitalova presents some legal and doctrinal limitations and gaps for the application of an integrated institutional approach to the development of future security and defence capabilities to counter hybrid threats.

Likewise, several papers discussed cybersecurity education and training, as well as technological aspects of countering hybrid threats. Dr. Vassileva and Dr. Zwilling identified some challenges and opportunities in hybrid warfare simulation-based learning. In addition, Col. Hristozov discusses the application of information and communication technologies and means of radio-electronic warfare in hybrid war. Finally, Mr. Kamenov stresses the need of intelligent methods for big data analytics in cyber security.

Last but not least, I would like to highlight some articles dedicated to the threat vectors identification in hybrid warfare. First of all, Dr. Avramov focuses on the conspiracy theories as a foreign policy tool in the arsenal of hybrid warfare. Besides, Dr. Yordanova provides an analysis the sovereign debt as emerging challenge of hybrid warfare. Moreover, Dr. Depuy discusses cyber-energy infrastructure vulnerabilities in 
the hybrid warfare environment and presented some US DoD mitigation efforts. Finally, Major Mahlyanovsfocused on the internet of things as a new attack vector in hybrid warfare.

Scientists and practitioners from NATO HQ, NATO Allied Command Transformation, NATO Joint Warfare Centre, U.S. Naval Postgraduate School, George C. Marshall Center for European Security Studies, the ministries of defence and various educational and research institutions from Bulgaria, Israel, Macedonia, New Zealand, Republic of Serbia and the USA presented their findings during the conference.

In conclusion, on behalf of the organizing committee of this important international conference, I would like to express our appreciation for the support of the leadership of the Ministry of Defence of the Republic of Bulgaria and G. S. Rakovski National Defence College.

Likewise, I would like to take this opportunity to express my gratitude to the coorganizer of the conference Mr Konstantin Zografov, AFCEA Sofia Chapter President and Regional Vice President for South East European Region.

Last but not least, the conference would not have been possible without successful public-private partnership and support on behalf of the industry. Therefore, I would like to extend our sincere appreciation to the partners from the industry: Intracom Bulgaria, TechnoLogica Ltd., Lirex.com IT Innovations, and Diehl BGT Defense.

\section{Acknowledgement}

The papers for the conference and, later, for this volume of Information \& Security, were reviewed and selected by an Editorial Board led by the editor of the volume and including Mr. Konstantin Zografov, AFCEA International, South East European Region Vice Chair and AFCEA Sofia Chapter Chair, Prof. D.Sc. Mitko Stoykov, Prof. Dr. Jordan Baev, Associate Prof. Dr. Maxim Karev, Colonel Associate. Prof. Dr. Ivan Hristozov, and Associate Prof. Dr. Branimir Zhekov - all from the Defence Advanced Research Institute, and Prof. Dr. Carol Atkinson from the Victoria University of Wellington, New Zealand. We kindly acknowledge their contribution in assuring the academic rigour and practical value of this volume.

We are also grateful to Ms. Greta Keremidchieva for her diligent work to make the language and style of some of the contributions up to the publication standards of "Information \& Security: An International Journal.” 


\section{Disclaimer}

The views and opinions expressed in this volume are responsibility of the authors and do not necessarily represent the views of the Bulgarian Ministry of Defence or the G. S. Rakovski National Defence College.

\section{About the author}

Captain (BGR-N) (ret.) Yantsislav Yanakiev is a full professor in sociology at the Bulgarian Defence Institute "Prof. Tsvetan Lazarov." He graduated from the Naval Academy in Varna, Bulgaria in 1982. After serving as a commissioned officer at Naval Base Varna, the Navy Headquarters and the Ministry of Defence, he applied for a doctoral study degree in 1988 at the Institute of Sociology, Bulgarian Academy of Sciences in Sofia, Bulgaria and received his Ph.D. in 1995. In addition, he acquired the degree of Doctor of Science in sociology from the same institute in 2009. He specialized as an International Research Fellow at the NATO Defence College in Rome, Italy in 1999 and at Cologne University, Germany in 2001 and 2007. He was a Fulbright Visiting Research Professor at the Defense Equal Opportunity Management Institute (DEOMI), Patrick Air Force Base, FL from October 2012 to March 2013. He has been a principal national representative to the NATO Science and Technology Organization Human Factors and Medicine Panel since 2005 and chaired Task Groups "Improving Organizational Effectiveness of Coalition Operations" and "Human Systems Integration Approach to Cyber Security." Professor Yanakiev received Individual Scientific Achievement Award of NATO Science and Technology Organization for 2018. He has published more than 200 monographs, articles and research papers in the field of the sociology of the military, human factors in defence organisations, different aspects of civil-military relations, interethnic relations in Bulgaria, in Bulgarian, English and Russian languages. 